\title{
O não espaço em Wesley Peres: narrativas líricas em deslocamento
} Rosane Carneiro Ramos ${ }^{1}$

\begin{abstract}
(94.) Pertenço mais às fraturas, sou casa entre vértebras. Um enigma me traga lentamente e me ri. É difícil suportar a afinidade que tenho com o vento e com as pedras. Ser eu é um sonho, tento me lembrar disso, de olhos abertos tento me lembrar disso. Meu enigma resulta da invenção: eu. Um tanto me revolto ante o fato de que desde já sou dissolução. Por isso, a casa, as paredes, a crença no dentro e no enigma que tento sustentar - pois não há enigmas, até eles fomos nós que inventamos: o que há não tem nome. E então que me sustento nisto: eu; finjo acreditar nesse mero caco de som que me permite mirar o estranho corpo no espelho e dizer: eu. Ah, minha inaptidão para a palavra que me comunique, que comunique qualquer coisa! Minhas palavras são para não dizer. Mas então por que falescrevo? Para não me deparar com a ausência absoluta? Para não experimentar a imbricação entre "eu" e vento? Para criar um silêncio e colocá-lo no lugar do silêncio impensável e informe, o silêncio que não é sequer silêncio ou enigma, um silêncio que simplesmente não é? Somos todos perversos; ao menos eu sou perverso, creio no que não creio, sustento o insustentável, ando com a eternidade nos olhos sabendo-me palha e eco (Peres, 2007, p. 129-130).
\end{abstract}

Wesley Peres é um escritor e psicanalista goiano, nascido em 1975. É autor de cinco livros: Água anônima (2001), Rio revoando (2003) e Palimpsestos (2007), de poesia; e dois romances, Casa entre vértebras (2007) e As pequenas mortes (2014). Em poesia recebeu, em 2002, o prêmio Cora Coralina, por Água anônima, enquanto seu primeiro romance, Casa entre vértebras, foi vencedor do Prêmio SESC de Literatura 2006. O surgimento bem-sucedido e a premiação de um romance poético em 2007 não chamou tanto a atenção da crítica, que se debruçou pouco sobre o aspecto do livro acerca da literatura de linguagem, e sobre a questão por alguns considerada talvez uma questão antiga, a do limite entre os gêneros literários. Houve mais, na verdade, uma tentativa de desvendar a trama, facilitando ao leitor uma abertura para a compreensão do romance. Porém, houve quem destacasse mais ciosamente a permeabilidade e o contato entre prosa e poesia, como Carlos Augusto Silva:

\footnotetext{
${ }^{1}$ Doutoranda em estudos portugueses e brasileiros no Department of Spanish, Portuguese and Latin American Studies do King's College London, Londres, Inglaterra. Pesquisadora da Capes. E-mail: rosane.ramos@kcl.ac.uk
} 
$\mathrm{Na}$ verdade, toda a tradição literária ocidental que problematiza a escrita, a expressão, a enunciação, em prosa ou verso, está contida na prosa poética de Wesley. O sucesso da obra muito se deve ao fato de que em nenhum momento o livro deixa de ser prosa ou poesia, mas capta e reorganiza o que ambas as modalidades discursivas tem de melhor em suas especificidades e capacidades distintas de expressar as contiguidades da alma humana (Silva, 2011).

Nas críticas esparsas feitas ao livro, é possível notar um desconforto na atribuição, afinal, do que seria a prosa poética, bem como parcas relações entre esta e a narrativa romanesca. A questão do espaço, em seu sentido denominador e tradicional, portanto, começa já pela localização/situação do que seria o recurso lírico aplicado ao romance. A busca por estabelecer um centro fixo narrativo nos moldes de uma trama romanesca tradicional, na verdade, denuncia de pronto seu deslocamento, como um lado em negativo do lugar e, ao mesmo tempo, uma (quase) ocupação diferente do espaço comumente destinado ao romance na literatura brasileira. Tal deslocamento parece patente quando abordados os romances poéticos na produção nacional.

Ao mapear-se esse deslocamento, surge, muitas vezes, o termo experimentação, aplicado por resenhistas e críticos literários quando se trata de textos menos referenciais e denotativos, não importando se menos ou mais metaforizados, se líricos ou não. Em uma entrevista para o jornal especializado Rascunho, de Curitiba, o próprio Wesley Peres debate o título de experimental, citando autores do século XX com romances de grande alcance público não necessariamente ligados a narrativas lineares, como Samuel Beckett, James Joyce, Virginia Woolf e, entre os brasileiros, Clarice Lispector e Osman Lins (Peres, 2013). $\mathrm{E}$, ocorre que, mesmo aceito o estilo menos referencial do romance contemporâneo, em face da chamada prosa poética - talvez para facilitar a compreensão de uma audiência mais abrangente, com vistas a satisfazer um nicho de mercado - recorre-se mais uma vez ao termo experimental como justificativa para um não aprofundamento do que possam significar outros recursos.

A aplicação do termo como valoração obscura e quase pejorativa por si só pede argumentação - lembrando Haroldo de Campos, remetendo a Theodor Adorno, "O que é fundamental é que exatamente a única possibilidade de fazer alguma coisa viva em nosso tempo é através da experimentação, experimentação que, em termos científicos, é o análogo 
do processo heurístico da descoberta" (Campos, 1977, pp. 54-55). Em acordo com esta linha de raciocínio, de fato a pecha sobre o experimental transforma um saudável processo de abertura em uma contenção, em uma etiqueta limitadora, ao contrário do que deveria sugerir a palavra - o que prejudica um natural movimento de pesquisa acerca de novas possibilidades narrativas.

Portanto, a investigação sobre tal deslocamento da narrativa poética na literatura brasileira não aponta apenas para mais uma vertente rica de estudos em grande parte inéditos; ela pode também se constituir como mais uma oportunidade de avanço sobre barreiras erigidas por nomenclaturas que, em busca de nomear para classificar, obstruem chances de conhecimento. A questão do espaço - ou não espaço, ou entre-espaço, como veremos a seguir - vem, então, a ser o eixo sobre o qual este artigo pretende contribuir para a discussão, apresentando a riqueza (aberta e sensorial) de interpretações que um romance lírico pode sugerir, além de apontar de forma sucinta como, em uma perspectiva maior, a narrativa poética parece inserir-se dentro de um histórico deslocado na historiografia literária nacional.

\section{Espaço, modo de falar}

Casa entre vértebras é sugerido como um romance que, se tratado em termos de trama narrativa, aborda um sujeito em crise tentando escrever cartas à mulher amada. Nas cartas - ou tentativas de - ele busca descrever-se, a pedido dela. Indica, em determinadas partes da história, estar em seu quarto. Na contracapa do livro, uma pequena resenha determina que o personagem encontra-se "preso em sua habitação", interpretando literalmente o sentido de casa. A personagem (sem nome) está sozinha em toda a narrativa, e sabemos de detalhes e opiniões da mulher amada - de nome Ana - por meio do que ele conta. ${ }^{2}$ O romance é dividido em tomos numerados, sendo cada tomo uma possibilidade de texto poético em si. Como poemas em prosa.

\footnotetext{
${ }^{2}$ Um detalhe significativo, o nome da mulher: "Ana”, que em tradução árabe significa $e u$. E Ana é a personagem feminina central de Lavoura arcaica, de Raduan Nassar (1989 [1975]), livro referenciado por Peres no texto, citando Nassar inclusive explicitamente, assim como as escritoras Orides Fontela (duas vezes), Gertrude Stein e Fernando Pessoa (Peres, 2007, p. 177, 152, 85 e 37, respectivamente).
} 
No entanto, em vez da casa propriamente, uma leitura sensível indica que o personagem pode estar em qualquer lugar. O lugar, em si, é conceito móvel, não se enquadra na perspectiva estabilizada comumente aplicada ao vocábulo. Portanto, tomando como exemplo a casa, ela pode ser feita de elementos ou teores diversos, pode ser desdobrada em múltiplos espaços, pode ser negada, ao ser denominada como também um "espaço de fora". Sua semântica é complexa, variada, de modo a proporcionar um permanente trânsito de sentidos, de percepções. Ela é, por fim, metaforizada poeticamente: “O nome habita a coisa, e minha casa é um lugar entre isso" (Peres, 2007, p. 62).

(43.) E, no fundo, águas me precedem e preveem. Minha casa é só um modo de falar das águas. Minha casa também me precede. [...] Penso, até e às vezes, que a casa precede as águas. Penso, ao contrário de Mileto, que a casa é a matéria dessas águas que instalam em meus ouvidos um barulho tão intenso quanto o que há entre uma e outra palavra - esse deusinho morto que me sonha (Peres, 2007, p. 58).

Fui eu mesmo que inventei essa casa vazia, com suas vértebras, com seus cômodos ocos onde há sempre lugar para os meus suicidiozinhos. Admito sim, essa obsessão por espaços dentro de espaços, daí, talvez, o meu fascínio por estar no entre um e outro espelho, o meu gosto por vinhos, a minha paixão por ler a textura do corpo sem buscar síntese (Peres, 2007, p. 68).

E é essa casa ambígua, ambivalente, plural, que o autor escolhe para denominar o livro, como símbolo máximo da desconstrução da mimesis que ele opera em sua narrativa. No título, já como anunciação, a casa é colocada "entre vértebras", em meio a uma estrutura fixa mas fragmentada. E todas as figuras cíclicas ao longo do romance - que contribuem para o padrão imagético necessário a todo romance lírico -, como a teia de aranha, a chuva, a pedra, a gaveta, o vento, são igualmente deslocáveis, digamos, de acordo com o filtro sensorial do protagonista/narrador. Deslocamento de sentidos, ou "estranha materialidade", como sugere a personagem. Para tudo há, como o narrador sugere, um dentro e um fora - um entre. O livro, se olhado sob o foco da espacialidade, todo ele pode ser uma grande reflexão sobre o tema.

(64.) Os rasgos negros do sol, num de meus sonhos, eram a imagem do universo visto do lado de fora, da vida registrada por fora. O lado de fora é um desejo antigo em mim. Nisso consiste o lado de 
fora? A casa não tem lado de fora; tudo porque a casa é o lado de fora - desde crianca sou dividido por entre dois rasgos, o fora e o dentro dos lugares (Peres, 2007, p. 87).

Da casa em deslizamento e de todos os artifícios que o narrador apresenta com vistas a desconstruir os abrigos dos sentidos, o conjunto inteiro da narrativa vai se contaminando. E, apesar de indicar que busca iniciar as tais cartas, "Sabe, é estranho me fazer palavras e me enviar e ser abrangido por seus olhos e me tornar matéria que alimente os continentes mais insólitos do seu pensamento" (Peres, 2007, p. 14), o narrador aos poucos desvela que talvez Ana sequer exista em um plano real: "Seja Ana quem for, ela, sempre a mesma e sempre outra" (Peres, 2007, p. 136). A linguagem encadeada de um tomo a outro, apesar da autonomia entre eles, sugere a intenção de estabelecer com o leitor um jogo tácito, no qual, afinal, a trama, a consecutividade, é secundária. Se há verdade em Ana, nas cartas, na figura mesmo do protagonista, em seus gestos e - o que nos interessa mais aqui - nos lugares, quando narrados, pode tornar-se ao leitor de pouca relevância. $\mathrm{O}$ desnovelamento da linguagem é o que sobe a primeiro plano.

E, nesse sentido, não o lugar, entendido em trânsito como o abordamos anteriormente, mas o espaço toma a frente. E aqui é relevante relembrar a diferenciação estabelecida por Michel de Certeau (2011) em A invenção do cotidiano (The practice of everyday life, título em inglês), quanto aos dois conceitos. Brevemente retomando, nas palavras de Certeau, o lugar seria uma ordem, "uma instantânea configuração de posições. Implica uma indicação de estabilidade" (Certeau, 2011, p. 117, tradução nossa), enquanto o espaço, levando em consideração a variação de direção, velocidade e tempo, "é composto da interseção de elementos móveis" (Certeau, 2011, p. 117, tradução nossa). Porém, conforme se observa no trabalho de Peres, a narrativa lírica é onde essa diferenciação é desafiada, visto que o lugar é desconfigurado de antemão em sua fixidez.

Então, sendo, de fato, um romance lírico - onde a consecutividade esvai-se em detrimento de um padrão de imagens metafóricas -, espacializa-se o tempo e o que nele é narrado, pessoas, acontecimentos e lugares. Esse tipo diferenciado de espacialização percorre a narrativa. E, agregando as considerações de Certeau e as teorias sobre as narrativas líricas, por espacialização do texto deve-se perceber uma 
espécie de eternização ou dilatação do instante narrado, como se o autor tornasse o tempo um espaço a ser explorado, como se mergulhasse no momento narrado.

Perceptivelmente, tal acepção incomum do espaço engendra novas construções sintáticas, que corporificam a espacialização da narrativa. O verbo "estar" sofre uma desarticulação, sendo questionado - visto que o lugar não é o território fixo. Em mais de um tomo, o autor repentinamente suprime o verbo, de forma tão flagrante que parece querer suscitar no leitor um susto, inquirindo também, de modo indireto, como num jump cut cinematográfico, num corte abrupto na sintaxe, a necessidade do leitor em localizar-se em meio à narrativa. O recurso reforça a despotencialização do "estar" em detrimento do "ser", o que configura uma das buscas da junção lírica entre narrador e mundo. Como no trecho a seguir: "Mas a coisa é ainda menos. Há tempos não sei onde você, onde essa carta para mim sempre algo tão impossível" (Peres, 2007, p. 30, grifo nosso), ou em:

Sei que minha história pode ser contada - se é que se trata mesmo da minha história -, contada por mim com mais eficácia falando de objetos, neles está registrado o impacto da dinâmica circunavegante do espaço - história ou ensaio. Portanto, tem algo em mim que me fala com total desconhecimento de tudo o que enredado em meu nome (Peres, 2007, p. 168, grifo nosso).

Peres também parece querer criar um atrito entre os dois verbos, aplicando-os de modo a causar estranhamentos. Ele os alterna em trechos inesperados, como em "sou o isso que tanto irrita você, matéria fria sangrando significações, tantas e nenhuma, sou o à beira disso, o à beira de todas as coisas, sou tanto em casa, tanto no quarto, tanto na gaveta" (Peres, 2007, p. 198, grifo nosso) ou, ainda, em: “Em casa, sou mais só. Em carta sou outro, e também nela estou só. Em casa sou mais estrangeiro" (Peres, 2007, p. 13). A repetição e a inapropriação do uso de "ser" e "estar" destacam ao leitor não o estado ou a localização da personagem, mas chamam a atenção para o próprio uso da linguagem, para, por meio do insólito, explicitar e deixar mais evidentes as questões essenciais do protagonista.

Toda a dinâmica em Casa entre vértebras opera a favor mesmo do que, ao final da leitura, sobressaem como temas principais da narrativa: a angústia existencial, o questionamento da identidade (dos marcos para sua construção) e a insuficiência da linguagem. Os 
poucos dados factíveis do protagonista, quando surgem, estão ligados a um testemunho da banalidade: ora a personagem encontra-se em uma conversa de botequim (p. 39), ora corta as unhas (p. 63), ora fixa o olhar sobre uma goteira (p. 109), ora encontra-se em um ponto de ônibus (p. 150), ora faz bolinhas com miolo de pão (p. 211). Ele menciona, inclusive, um diagnóstico médico, acusando um problema de cotidiano:

Quem sabe não se poderia falar de um certo gosto pelas tardes amarelecidas de domingo, quando até o vento se recusa a se mover. E outras coisas mais, ainda. Ler cadernos de resenha; dormir de olhos abertos; colecionar bilhetes de entrada de uma peça de teatro ou de um jogo de futebol a que assistiu na infância; ler $O$ inominável durante as férias; gostar de pescar, mas não de pegar o peixe. E olha que, mesmo assim, o médico me deu o diagnóstico de "cotidiano muito restrito". Bom, pelo menos ele ainda concebe que eu tenha um cotidiano. O que não se perdoa mesmo é alguém que sofre de "ausência de cotidiano" (Peres, 2007, p. 83).

O marasmo da vida do protagonista contrasta com a exuberância da linguagem e do pensamento, na grande maioria do texto. No caso de Casa entre vértebras, dir-se-ia que o contraste é maior ainda, dada a monotonia apontada pelo lado referencial da narrativa, que, caso também possa indicar uma trama referencial - para o leitor que optou por rejeitar o acordo com a linguagem, e não mergulhou na história -, seria a da tensão causada pela possibilidade de escrita ou não das cartas. Seria possível a esse homem enviá-las ou não?

Porém, caso se deixe imiscuir, o leitor pode observar como a narrativa suplanta o contraste: o narrador realiza na linguagem uma transcendência do real, por meio da transfiguração do entorno, efetuada em sua consciência. E, dos meros objetos, ordinárias situações e mesmo dos mais triviais pensamentos ele opera um salto metafórico que, além de colocar a linguagem em evidência, introduz questões ontológicas que através de uma narrativa denotativa mais linear talvez não fosse possível fazê-lo.

Talvez uma leve inclinação dos lábios em silêncio, talvez uma pinta no entorno do umbigo, talvez, talvez, nenhuma palavra pode mesmo explicar por que, de repente, o pensamento se torna monolítico, e as palavras pensadas circulem em torno de um nome, um nome que circula em torno de um corpo que parece 
construído para redemoinhar esta água anônima que inflama o meu próprio corpo (Peres, 2007, p. 91).

\section{Tempo e espaço no romance lírico}

As coordenadas sobre espaço, assim como sobre tempo, são cruciais para a análise da narrativa lírica no romance. A começar pelo conceito criado pela ensaísta inicial da matéria, Virginia Woolf - o momento. Ao buscar elucidar a nova prosa que se apresentava na Europa no início do século XX, Woolf elaborou um conceito que ainda hoje vem a influenciar o estudo da narrativa contemporânea, especialmente a lírica. ${ }^{3} \mathrm{O}$ conceito de momento, segundo a autora, pressupõe um tipo diferente de consciência, uma consciência extra e sensitiva acerca da própria lógica do escritor. Poderíamos também entender esse instante como de apreensão pelo autor de sua própria sensibilidade acerca do mundo. Woolf costumava referir-se ao momento como "momentos de ser" - o que tornava, para ela, as narrativas realistas, estritamente ligadas ao referencial, ao denotativo, constituídas por "momentos de não ser" (Woolf, 1965, p. 129, tradução nossa).

Eu pretendo eliminar todo desperdício, insipidez, superfluidade: quero doar o momento inteiro, com o tudo o que ele contiver. Vamos dizer que o momento seja a combinação de pensamento, ação, a voz do mar. Desperdício, insipidez, surgem da inclusão de coisas que não pertencem ao momento, esse terrível negócio da narrativa realista: ir do almoço ao jantar: é falso, irreal, meramente convencional (Woolf, 1965, p. 139, tradução e grifo nossos).

Aderindo ao conceito (que também é apresentado como uma técnica), Ralph Freedman, principal teórico acerca da narrativa lírica, esclarece que é o momento que permite ao escritor encontrar o equilíbrio entre poesia e prosa (Freedman, 1963, p. 193), e ele o demonstra por meio dos romances por ele considerados os mais líricos de Woolf, como Mrs. Dalloway, To the lightouse e The waves. Segundo ele, o momento seria o casamento entre a cena narrada e a sensibilidade do escritor.

\footnotetext{
${ }^{3}$ Charles Schug, em The romantic genesis of the modern novel, aponta uma tênue associação entre o germe literário de Henry James, a epifania de James Joyce e o momento de Woolf, todos sob influência do Romantismo (Schug, 1979, p. 85). Ele sustenta que a estética romântica teve impacto contínuo na literatura dos séculos XIX e XX, sendo crucial para as grandes mudanças observadas na forma do romance ao final do século XIX (Schug, 1979, p. 10).
} 
Na verdade, o conceito de Woolf determina uma complexa operação que se pode buscar explicar sucintamente como a percepção do escritor sobre sua própria percepção, e a tentativa de esboçá-la, sem, no entanto, buscar fechá-la em uma denominação. “Em sua ação formal a poesia começa com o eu, mas se encaminha à despersonalização. Um processo similar ocorre na narrativa lírica. Mundos em tempo e espaço não são reproduzidos precisamente, mas rearranjados em disposições estéticas que se tornam universais e simbólicas" (Freedman, 1963, p. 188, tradução nossa). Ele acrescenta ainda que o protagonista lírico é um errante pelo espaço e pelo tempo. Quanto à errância, é importante lembrar novamente de Certeau, no destaque que ele dá aos errantes, que ele chama de praticantes ordinários das cidades: "Esses praticantes fazem uso de espaços que não podem ser vistos; seu conhecimento acerca deles é tão cego quanto o dos amantes nos braços um do outro" (Certeau, 2011, p. 93, tradução nossa).

Em uma analogia à narrativa, a errância pelas coordenadas referenciais de espaço e tempo é apontada do mesmo modo por outros teóricos sobre lirismo na narrativa. Da Espanha, temos Darío Villanueva e Ricardo Gullón, que realizaram estudos em obras de autores como Azorín, Gabriel Miró, Ramón Pérez de Ayala e Benjamín Jarnés; e, de Portugal, Teresa Maria Goulart, que realizou pesquisa sobre o trabalho de Vergílio Ferreira. Ricardo Gullón aponta que essa espacialização do tempo em uma narrativa lírica indica, na verdade, uma relação mais íntima entre tempo e espaço (Gullón, 1984, p. 21, tradução nossa). Já Darío Villanueva chama a atenção para a nova demanda que se estabelece sobre o leitor perante essa operação - ou, seu deslocamento. “O predomínio lírico do espaço impõe uma determinada atitude do leitor; fixa sua atenção sobre a textura estilística da escrita, na qual prevalece o substantivo sobre o verbal; e substitui, desse modo, a característica ação da narrativa pelo estatismo contemplativo da lírica" (Villanueva, 1983, p. 20, tradução nossa). O engajamento sensível do leitor, como se percebe, caracteriza um dos mais interessantes aspectos do tema, que para não nos desviarmos do objetivo geral do artigo preferimos não desenvolver aqui.

O francês Jean-Yves Tadié, especializado na obra de Marcel Proust, aponta que ocorre um deslizamento de níveis da leitura de cada frase na narrativa lírica. Por isso, o espaço dessa narrativa é sempre um outro lugar, como um "guia simbólico de viagem", no qual as imagens 
afastam-se ou justapõem significados, por meio de metáforas ou metonímias. "O espaço do mundo, tal como o livro o representa, é de acordo com o espaço da linguagem encarnada nas figuras e, ao mesmo tempo, faz com que o espaço livre-se do papel subordinado de cenário ou aperitivo que ocupa no romance clássico, sob o nome de descrição" (Tadié, 1978, p. 10, tradução nossa). Ele ressalta a circularidade da narrativa, com a recorrência de temas e sons, a exemplo, além da poesia, também da música. Na escrita de Wesley Peres a sonoridade é uma constante, por vezes mais, por vezes menos, interpenetrando a leitura e o ritmo mesmo dos meandros internos do protagonista: "Fixar-se numa ficção, até o amor é isso; até mesmo sonhar é isso. Um isso, desses que vivem na sombra, me disse nada, e é isso que me assombra" (Peres, 2007, p. 111). Aliterações, assonâncias, antíteses e rimas reforçam o apelo ao som, orquestrado de acordo com a tensão desejada pelo autor.

Todo esse procedimento requer do leitor uma radicalização do engajamento: ou ele penetra - deixando-se impregnar pela narrativa ou em absoluto não consegue fazê-lo, sob pena de não apreender da escrita. Quase um pacto com a sensibilidade, do autor e a própria, a mesma que se requer do leitor de poesia. Torna-se necessária uma visão - percepção - mais sensível, interpenetrante, englobadora, a mesma que o protagonista lírico exercita, olhando e se imiscuindo a objetos, lugares e pessoas, em uma espécie de desdobramento - a que tomamos a liberdade de aqui de sugerir como espacialidade.

Essa visão, muito mais ampla, visão de dentro, além e no entorno do próprio homem, opera, como diz Maurice Merleau-Ponty, uma transubstanciação do mundo. Em $O$ olho e o espírito, Merleau-Ponty aponta para o fenômeno na atividade da pintura. De modo convergente, os estudos sobre narrativas líricas realizam invariavelmente analogias à pintura, em especial a impressionista, nas quais, apesar da fragmentação, a percepção da obra ocorre de forma imediata a partir do momento da apreensão das imagens como um todo. O mesmo ocorreria na narrativa lírica. ${ }^{4}$ Ponty afirma que as coisas olham o artista, e que este deve ser trespassado pelo universo, e não o contrário (Merleau-Ponty, 2003, p. 26).

\footnotetext{
${ }^{4}$ A associação entre prosa lírica e os movimentos impressionista e pós-impressionista na pintura teve grande ímpeto a partir do Grupo de Bloomsbury. Roger Fry, crítico, pintor e professor integrante do grupo, desenvolveu bastante a ideia, sendo seguido por Virginia Woolf em seus ensaios. A respeito, veja Vision and design, publicado originalmente pela Chatto \& Windus (Londres, 1920) e republicado pela Oxford University Press (Londres, 1981).
} 
Tal processo de transubstanciação, de trespassamento do artista pelo mundo, pode corresponder à similar operação de espacialização ocorrida na narrativa lírica. Como se espacializar o tempo em verdade demandasse esse tipo de capacidade.

$\mathrm{Na}$ teoria de Ralph Freedman, vamos encontrar a ocasião para esse tipo de ocorrência em sua prerrogativa de que no romance lírico, tal como no poema, acontece uma junção do eu e do mundo. O protagonista corresponderia ao eu lírico do poema, e é por meio dele que ocorre a transfiguração do mundo em padrões imagéticos, deslocando a ação para a intensidade das percepções do narrador, na chamada progressão lírica objetiva.

\section{O entre lugar do lirismo narrativo}

The lyrical novel, tese de Freedman defendida em 1953 em Yale, nos Estados Unidos, e publicada uma década depois, ainda hoje é referência central para os estudos realizados acerca desse tipo de escrita. Em uma rigorosa análise de autores como Virginia Woolf, André Gide e Herman Hesse, o texto demonstra as singularidades de um gênero híbrido nascido a partir das transformações apresentadas pelo romance ao longo do século XX. ${ }^{5}$

Na narrativa tradicional, o mundo é a questão e é o que existe além de ambos, escritor e leitor. Na narrativa lírica não é um universo onde os homens praticam suas ações, mas uma visão do poeta modelada como um desenho. O mundo é reduzido a um ponto de vista lírico, o equivalente ao eu do poeta: o eu lírico (Freedman, 1963, p. 8, tradução nossa).

Entre todos os atributos apresentados em sua teoria, destaca-se o caráter absolutamente suscetível das narrativas líricas; elas, em verdade, podem variar muito de acordo com as idiossincrasias de autores e de complexas técnicas aplicadas sobre narrativas-base. Isso significa dizer que seu principal aspecto não é uma forma em si - até porque ela é

\footnotetext{
${ }^{5}$ Questiono em minha pesquisa de doutorado a denominação de hibridização, em vista das transformações ocorridas na teoria dos gêneros. As nomenclaturas para a narrativa e o romance lírico, se gêneros, subgêneros, modos, categorias ou estilos, ou outras mais, do mesmo modo, coloco em questionamento. Por serem questões teóricas muito abrangentes, não serão abordadas neste texto.
} 
mutável -, mas a maneira como se utiliza do formato da narrativa original escolhida. Tomado como exemplo, Casa entre vértebras apropriase do que poderia ser considerado um romance epistolar contemporâneo para seu desenvolvimento como romance lírico. O resultado é que, ao utilizar a prosa poética, Peres desvirtua o estatuto básico do texto epistolar, cuja intenção original, por meio das cartas, é dar mais verossimilhança ao texto.

Essa "sensibilidade literária", esse "modo de abordagem", apresenta, portanto, traços sutis de identificação (Freedman, 1963, p. 10-14, tradução nossa). Ele desenvolve ainda a ideia de que o romance lírico configura-se uma instância do romance de consciência, com a diferença de que este último apresentaria apenas conteúdo mental, sem o necessário uso lírico da mente (Freedman, 1963, p. 273, tradução nossa). Por uso lírico da consciência podemos indicar, como característica mais forte, um padrão imagético nascido da metaforização realizada pelo protagonista. O protagonista, chamado herói simbólico, é o lócus onde ocorrem todas as transfigurações do mundo externo em contato consigo. As transubstanciações são operadas por meio de sua consciência, em uma junção de seu mundo interno com o mundo ao redor.

A textura imagética, por meio da linguagem, é o ponto principal e prepondera sobre a trama narrativa, sobrepujando a causalidade e a temporalidade características dos romances mais referenciais. Isso significa dizer também que uma narrativa lírica não se faz apenas pela escrita formal da prosa poética, com assonâncias, aliterações, rimas e todas as demais características corpóreas da poesia, mas principalmente por seu caráter imagético metaforizado. As complexas características do romance lírico, apresentadas aqui em um resumo apenas introdutório, parecem ter criado também complicações para seu estudo. Ainda hoje, não são muitos os estudiosos dedicados ao tema. Some-se a esse fator a particularidade de mudanças na teoria dos gêneros e as inúmeras transformações ocorridas no século $X X$ durante a evolução do romance, hoje compreendido como obra aberta, no sentido dado por Umberto Eco.

No entanto, talvez em consonância e em sincronicidade (porém, em relação dialética, é minha hipótese, o que originaria outro artigo) com o advento da chamada sociedade da imagem (vide Guy Debord e Jean Baudrillard), a narrativa interiorizada abundante em imagens cresce em ocorrência e, não em poucas ocasiões, surge acompanhada de intensa metaforização gerada pelo afloramento da psique. Não que, em si, o fato 
configure tais narrativas como líricas em absoluto, mas parece valer a pena uma análise acerca de um fenômeno que se aproxima em termos do que Otavio Paz, já em 1956, ano de lançamento de O arco e a lira, apontava apaixonadamente como um retorno do romance ao poema, de acordo com as mutações que lhe são características (Paz, 1956, p. 226-227).

No Brasil, uma visão panorâmica sobre autores contemporâneos que lançam mão de vigorosa carga lírica imagética nos revelam alguns nomes indicativos, como o próprio Wesley Peres, José Geraldo Neres, Daniela Lima, Adriana Lisboa. Dentre a multiplicidade e a heterogeneidade apontadas na literatura brasileira pela crítica mais recente, todos poderiam estar contemplados no conjunto de autores representantes de uma forte subjetividade - mesmo como força reativa diante da pressão homogeneizadora do mundo globalizado, conforme assinala Beatriz Resende.

É nessa obliquidade dos discursos anti-hegemônicos que aparecem recursos que dão formas múltiplas à criação literária contemporânea: a apropriação irônica, debochada mesmo, em alguns casos, de ícones de consumo; a irreverência diante do politicamente correto; a violência explícita despida do charme hollywoodiano; a dicção bastante pessoalizada, voltada para o cotidiano privado; a memória individual traumatizada, seja por momentos anteriores da vida nacional, seja pela vida particular; a arrogância de uma juventude excessiva; a maturidade altamente intelectualizada; a escrita saída da experiência acadêmica e assim por diante, como continuaremos vendo (Resende, 2008, p. 20).

E talvez esses autores pudessem também ser herdeiros em certo grau do que nos estudos tradicionais da literatura brasileira estipulou-se chamar romance intimista, ou ainda introspectivo ou psicológico, de presença destacada especialmente até a década de 1970 do século XX. ${ }^{6}$ No entanto, um olhar mais atento sobre a autoria mais subjetivista, mesmo nos escritores das gerações passadas, mereceria em si uma reanálise, se a hipótese da descendência fosse aprofundada neste

\footnotetext{
${ }^{6} \mathrm{O}$ romance intimista poderia ser cogitado como sua matriz literária, para utilizar uma expressão cunhada por Tania Pellegrini. A pesquisadora desenvolve a ideia de que aspectos considerados novos dentro da atual fertilidade da literatura nacional podem ter como fundação e linhagem títulos de épocas anteriores, acrescidos de inéditos enfoques em conteúdo e forma. É preciso destacar, todavia, que seu artigo localiza matrizes literárias a partir do período ditatorial no Brasil. Ver seu artigo "Relíquias da casa velha: literatura e ditadura militar, 50 anos depois" (Pellegrini, 2014).
} 
estudo. A subjetividade preponderante de autores como Lúcio Cardoso, Otávio de Faria, Cornélio Pena, Ciro dos Anjos, Aníbal Machado, Osman Lins e Lygia Fagundes Telles, em alguns de seus títulos, parece ter-lhes dado acesso a esse grupo intimista, porém a gradação entre os aspectos introspectivos de suas narrativas permaneceu a descoberto.

Daí que a respeito de autores como Lúcio Cardoso, de forte metaforização imagética, por exemplo, é possível encontrar apreciações de sua escrita como introspectiva e sensorial e, ainda, onírica e existencial, bem como outras denominações que nublam a fruição de seu trabalho. "Quando a tensão 'para dentro' chega a seu limite, o fluxo da consciência recupera as imagens da natureza (líquido, chama, praia, treva...) como símbolo e metáfora. E começa a ser penoso distinguir a prosa da poesia" (Bosi, 1994, p. 414-415).

$\mathrm{E}$, se uma análise de autores estranhamente subjetivos é realizada ainda em perspectiva maior, abarcando talvez parte do século XIX, podemos vir a encontrar toda uma gama de escritores que extrapolaram suas narrativas. Como exemplos, podem ser citados Adelino Magalhães (década de 1920), considerado por Sonia Brayner (1979) como dotado de potente lirismo em sua escrita inovadora, ${ }^{7}$ e provavelmente até um autor (poeta) como Sousândrade, que teve O Guesa errante, de 1877, cogitado mesmo como "poema-romance", segundo Joaquim Serra (Serra apud Campos, 1977, p. 24). Mas então talvez estivéssemos já tentando contemplar o que a história tradicional da literatura brasileira não chegou a apreciar.

Traçar uma retrospectiva nessa seara de anticanônicos ligados ao lirismo na narrativa de fato não é tarefa simples. Mas por força e graça do porvir surgem autores como Clarice Lispector, que, dos muitos estudos que suscitou, entre eles está o de sua verve poética. É com Lispector que o intimismo, de tão simbólico e metafórico, passa então a ser considerado experimental - e retomamos aqui o argumento inicial deste artigo, sobre o termo. A partir de Clarice, que pela potência da escrita desarranja a classificação canônica, que a narrativa psicológica passa a ser observada sob uma perspectiva mais em aberto. 8,9

\footnotetext{
${ }^{7}$ Adelino Magalhães também chega a ser vinculado ao Impressionismo por pesquisadores como Andrade Muricy, em Panorama do movimento simbolista brasileiro (1973 [1952]).

${ }^{8}$ Cabe aqui uma leve indicação da importância de técnicas narrativas como o fluxo de consciência e o monólogo interior, que hoje estão incorporadas a grande parte dos métodos dos escritores. Nos
} 
E, ainda um pouco mais adiante na cronologia dos autores observados pela historiografia oficial, surge Raduan Nassar, como outro ponto cardeal para essa intrincada teia de líricos não devidamente assimilados até a contemporaneidade. Lavoura arcaica - que, já vimos, é influência explícita em Wesley Peres - forçou as análises literárias pelo encontro da prosa tradicional com a poesia, pela evidência mais que exuberante de sua prosa poética. Como registrou ainda Alfredo Bosi: "Um romance intimista cujo trabalho formal levou a linguagem às fronteiras da prosa poética foi a estreia de Raduan Nassar, Lavoura arcaica, em 1976 [sic]" (Bosi, 1994, p. 423).

Em pesquisa pelos historiadores e críticos mais referendados na literatura nacional, depara-se com o fato de que a outra única ficção brasileira considerada lírica é Iracema (1965 [1865]), de José de Alencar. Cabe, então, ressaltar que essa investigação mais aprofundada em termos retrospectivos nos leva, dentro da historiografia nacional, a circunstâncias que oferecem um bom campo para novos estudos. Chega-se, assim, à apropriação ideológica do lirismo pela literatura do Romantismo com vistas à construção da identidade nacional; pela posterior depreciação do lirismo, quando já não poderia engajar-se no retrato da nação; pela resistência inicial nos estudos literários ao Simbolismo, especialmente a prosa; e ainda ao deslocamento de escritores modernistas ligados à narrativa poética; sem mencionar seu desprestígio em épocas ditatoriais e pós-ditatoriais, quando uma literatura engajada na prosa era o mais cobrado.

Mas tal vereda imensa, é de se notar, extrapola os propósitos deste artigo. Em alguns poucos parágrafos tentei apenas demonstrar como pode vir a ser importante destrinchar uma hipótese fundadora de uma linhagem de escritores que, no final do século $X X$, venha a influenciar autores em prosa contemporâneos dotados de inegável carga subjetiva, muitas vezes acentuadamente lírica. Percebo, nessa negação do passado lírico na prosa brasileira do século $X X$, uma espécie de sombra que jaz sob o estranhamento com que alguma crítica atual - especializada e dos leitores - reclama a respeito da excessiva subjetividade dos autores contemporâneos, sua ênfase na diç̧ão pessoal, na transposição de seu

estudos das narrativas psicológica e lírica as duas técnicas apresentam especial relevância, o que contribui muito para diferenciacões entre os dois estilos de romance.

${ }^{9}$ Veja Instantes líricos de revelação (2013), de Mariangela Alonso, editado pela Annablume, para um estudo mais recente de Clarice Lispector sob o viés poético. 
mundo interno por imagens. Esses autores, hoje, retratam principalmente a vida urbana. Mas creio não tenham surgido do nada, apenas da vivência como cidadãos do mundo globalizado na era da imagem.

Outro aspecto interessante a destacar é a aproximação, pela narrativa lírica, dos autores brasileiros com os demais autores latinoamericanos. Clarice Lispector como romancista lírica, por exemplo, mereceu já aprofundados estudos de pesquisadores como Earl Fitz, dos Estados Unidos. Segundo Fitz (1979), Lispector seria “a principal romancista lírica do Brasil", o que ele demonstra em extensos ensaios sobre A maçã no escuro (1998 [1961]), para ele sua ficção lírica medular. O pesquisador reúne Lispector a outros autores latino-americanos como Juan Carlos Onetti, José Donoso, Carlos Fuentes e Lezama Lima, para ele também detentores de potente escrita lírica. Tal desdobramento vislumbra do mesmo modo uma importante vertente a ser investigada, em termos da escrita contemporânea brasileira, quando situada em termos continentais. ${ }^{10}$

A prosa lírica na literatura brasileira contemporânea, tanto quanto a de seus predecessores negligenciados ou esquecidos, merece ainda apurada pesquisa. Seu desdobramento pode abrir perspectivas frutíferas, lançando luzes tanto sobre o passado quanto sobre o futuro, permitindo, no presente, a possibilidade de um entre-espaço instigante para interessados na literatura nacional.

\section{Referências}

ALENCAR, José de (1965 [1865]). Iracema. In: Obras completas. Rio de Janeiro: Companhia Aguilar. v. 3.

ALONSO, Mariangela (2013). Instantes líricos de revelação: a narrativa poética em Clarice Lispector. São Paulo: Annablume.

BADANO, Cecilia M. T. LÓPEZ (2010). La novela historica hispano-americana entre dos siglos: un caso: Santa Evita: cadáver exquisito de paseo por el canon. Madrid: Consejo Superior de Investigaciones Científicas.

\footnotetext{
${ }^{10} \mathrm{O}$ romance histórico contemporâneo latino-americano, por exemplo, tem sido objeto de estudos quanto a sua capacidade de reapresentar e repensar identidades, pela desconstrução da representação e da historiografia tradicionais. O tema é explorado no livro La novela historica hispano-americana entre dos siglos (2010), de Cecilia M. T. López Badano.
} 
BOSI, Alfredo (1994). História concisa da literatura brasileira. 42. ed. São Paulo: Cultrix.

BRAYNER, Sonia (1979). Labirinto do espaço romanesco. Rio de Janeiro: Civilização Brasileira; Brasília: Instituto Nacional do Livro.

CAMPOS, Haroldo de (1977). Ruptura dos gêneros na literatura latino-americana. São Paulo: Perspectiva.

CERTEAU, Michel de (2011). The practice of everyday life. Berkeley: University of California Press.

FITZ, Earl E (1979). The rise of the new novel in Latin America: a lyrical aesthetic. Inter-Muse: an interdisciplinary journal, n. 2, p. 17-27.

FREEDMAN, Ralph (1963). The lyrical novel. London: Oxford University Press.

FRY, Roger (1981 [1920]). Vision and design. London: Oxford University Press.

GULLÓN, Ricardo (1984). La novela lírica. Madrid: Catédra.

LISPECTOR, Clarice (1998 [1961]). A maçã no escuro. Rio de Janeiro: Rocco.

MERLEAU-PONTY, Maurice (2003). O olho e o espírito. Lisboa: Passagens.

MURICY, José Candido de Andrade (1973 [1952]). Panorama do movimento simbolista brasileiro - Parte 1. 2a ed. Brasília: Conselho Federal de Cultura e Instituto Nacional do Livro. (Coleção de Literatura Brasileira, n. 12).

NASSAR, Raduan (1989 [1975]). Lavoura arcaica. 3. ed. São Paulo: Companhia das Letras.

PAZ, Octavio (1956). El arco y la lira. México: Fondo de Cultura Econômica.

PELLEGRINI, Tania (2014). Relíquias da casa velha: literatura e ditadura militar, 50 anos depois. Estudos de Literatura Brasileira Contemporânea, n. 43, p. 151-178, jan./jun.

PERES, Wesley (2007). Casa entre vértebras. Rio de Janeiro: Record.

PERES, Wesley (2013). Literatura sem deus. Rascunho, n. 158, jun. Disponível em: <http://rascunho.gazetadopovo.com.br/literatura-sem-deus/>. Acesso em: 10 dez. 2014.

RESENDE, Beatriz (2008). Expressões da literatura brasileira no século XXI. Rio de Janeiro: Casa da Palavra.

SCHUG, Charles (1979). The romantic genesis of the modern novel. Pittsburgh: University of Pittsburgh Press; London: Feffer and Simons. 
SILVA, Carlos Augusto (2011). O livro-linguagem. Jornal Opção, n. 1.859, 20-26 fev. Disponível em: <http://www.jornalopcao.com.br/posts/opcao-cultural/olivro-linguagem>. Acesso em: 15 dez. 2014.

TADIÉ, Jean-Yves (1978). Le récit poétique. Paris: PUF.

VILLANUEVA, Darío (Ed.) (1983). La novela lírica 1: Azorín, Gabriel Miró. Madrid: Taurus.

WOOLF, Virginia (1965). The writer's diary: being extracts of the diary of Virginia Woolf. 4. ed. London: The Hogarth Press.

Recebido em agosto de 2014.

Aprovado em dezembro de 2014.

resumo/abstract

\section{O não espaço em Wesley Peres: narrativas líricas em deslocamento}

Rosane Carneiro Ramos

Este artigo pretende abordar a representação do espaço em Casa entre vértebras (2007), de Wesley Peres, demonstrando como a narrativa lírica, por meio da linguagem não referencial e metafórica, pode introduzir novos questionamentos ao tema. Em acréscimo, em uma perspectiva maior intenciona também apresentar sucintamente princípios teóricos do lirismo na narrativa e, ainda, o deslocamento dos romances líricos nos estudos da historiografia literária nacional.

Palavras-chave: espaço, narrativa lírica, historiografia literária, Wesley Peres.

\section{The non space in Wesley Peres: lyrical narratives displacement}

\section{Rosane Carneiro Ramos}

This essay aims to address the issue of space in Wesley Peres' Casa entre verrtebras (2007), by showing how the lyrical narrative, through non referential and metaphorical language, can introduce new questions to the subject. Furthermore, in a broader perspective, it intends to briefly present some theoretical principles of lyricism in narratives and the displacement undergone by lyrical novels in national literary historiography as well.

Keywords: space, lyrical narrative, literary historiography, Wesley Peres. 